\section{Electroluminescent Panels as Pulsed Fiducial Marks in Spark Chamber Experiment*}

\author{
Arpad Barna and Michael N. Kreisler $\dagger$ \\ Stanford University, Stanford, California 94305 \\ AND \\ Michael J. Longo \\ University of Michigan, Ann Arbor, Michigan 48103
}

(Received 22 November 1965; and in final form, 9 December 1965)

$\mathrm{E}^{\mathrm{L}}$ LECTROLUMINESCENT panels can provide convenient and relatively inexpensive means of placing fiducial marks on spark chamber pictures. ${ }^{1,2}$ These panels consist of a sandwich of a transparent electrode, a phosphor imbedded in a dielectric, and a metal electrode. Light is produced when a varying electric field is applied to the phosphor. ${ }^{3}$ The main advantages of using pulsed electroluminescent panels over the usual system employing reticles illuminated by flash tubes are:

(1) They improve accuracy, since the edges determined by the fiducial marks are very well defined.

(2) They are convenient for experiments designed to use automatic film reading systems.

(3) In many cases they allow a more flexible arrangement of the fiducials.

(4) Under suitable operating conditions they are extremely reliable.

The panels are available in a variety of sizes and shapes; the ones used here ${ }^{4}$ were $0.8 \mathrm{~mm}$ thick with $0.8 \mathrm{~mm}$ copper leads along two edges, and a $3 \mathrm{~mm}$ unlighted perimeter.
In order to measure the relative light intensity as a function of the operating conditions, a $1 \times 5 \mathrm{~cm}$ panel was mounted on the face of a 53AVP photomultiplier tube with twelve layers of masking tape attenuating the light. The panel was driven through a current limiting resistor by a pulsed square wave generator described below; the output signal of the tube was displayed on an oscilloscope. For square wave bursts of 5 to $10 \mathrm{msec}$, it was found that the light intensity increased with the square of the applied voltage, and as a function of frequency the intensity exhibited a flat maximum between 4 and $8 \mathrm{kc}$.

Two series of life tests were performed. In the first one, a $12 \mathrm{~cm}^{2}$ panel was flashed 10 times a second by a $500 \mathrm{~V}$, $10 \mathrm{kc}$ square wave burst of $4 \mathrm{msec}$ duration; the maximum current was limited to $25 \mathrm{~mA} / \mathrm{cm}^{2}$ by a series resistor. Using Polaroid film, only a small decrease in the light intensity was observed after 1.5 million flashes, and there was no further noticeable change for an additional 5.5 million flashes. A second test was performed on four parallel $5 \mathrm{~cm}^{2}$ panels driven by a square wave burst with a length of 10 $\mathrm{msec}$, voltage of $500 \mathrm{~V}$, and a frequency of $5 \mathrm{kc}$; the maximum current was limited to $25 \mathrm{~mA} / \mathrm{cm}^{2}$. Pulsed at a rate of 1.5 pulses/sec, the light output observed by a photomultiplier tube decreased to $80 \%$ of its original value in 50000 pulses and to $68 \%$ after 170000 pulses. No panel tested could withstand dc voltages in excess of $750 \mathrm{~V}$, or a $600 \mathrm{~V}, 20 \mathrm{kc}$ square wave burst of $1 \mathrm{sec}$ length.

A schematic of the transistorized square wave generator capable of delivering $10 \mathrm{~A}$ at $500 \mathrm{~V}$ with a risetime of $<5 \mu \mathrm{sec}$ is shown in Fig. 1. Power supplies, low power square wave source, and gating circuitry are not shown. ${ }^{5}$

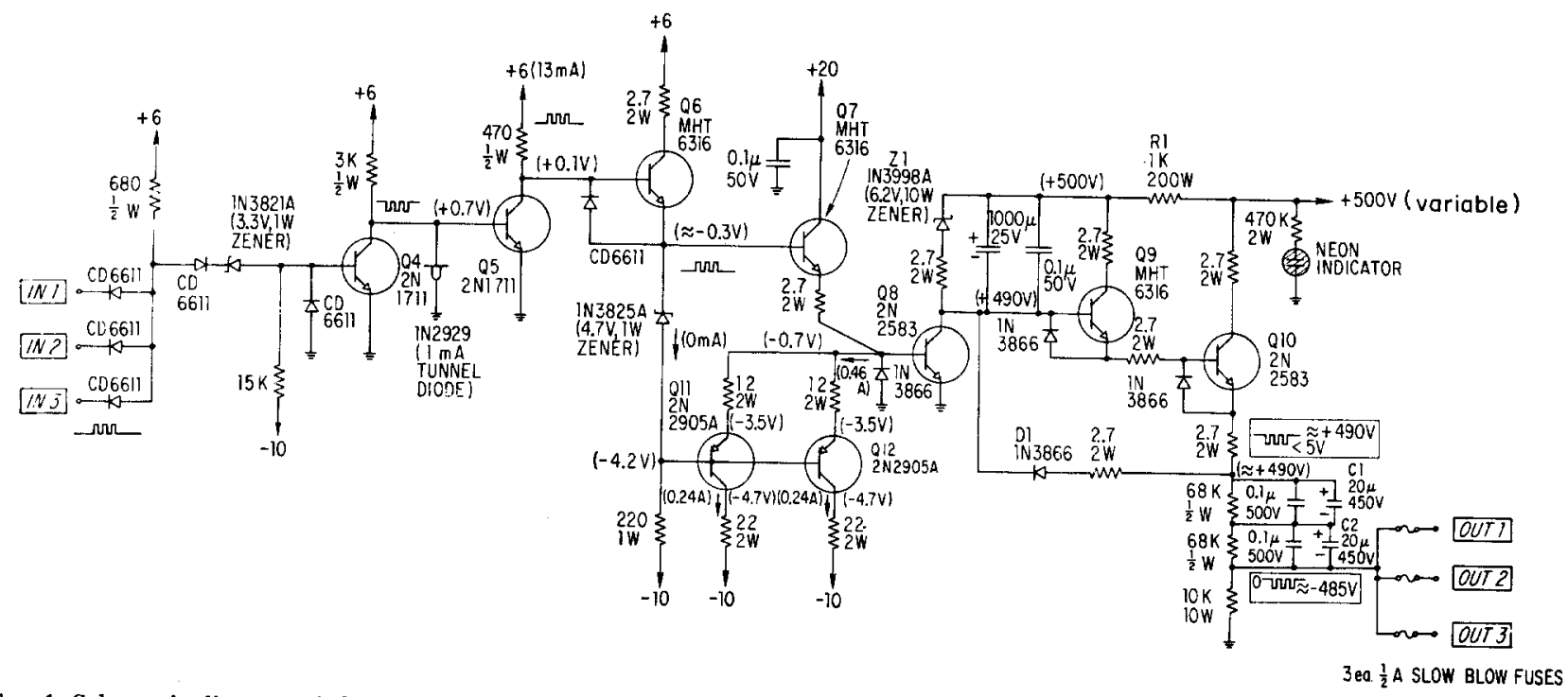

Fig. 1. Schematic diagram of the square wave generator. Not shown are power supplies, low power square wave source, and gating circuitry. Quiescent currents and voltages are noted in parentheses. Transistors Q7 through Q12 and Zener diode $\mathrm{Z1}$ are mounted on heat sinks. Transistors 


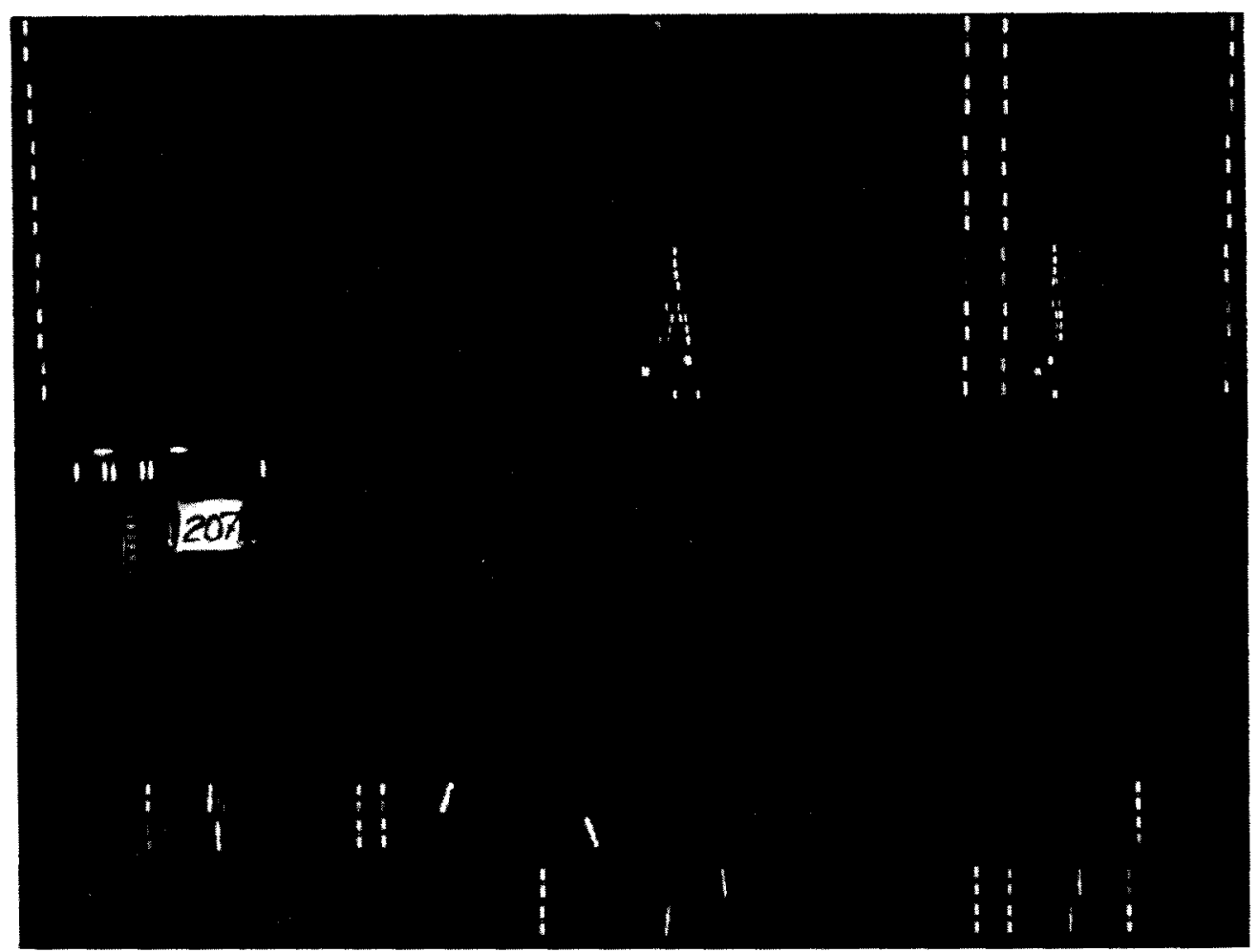

FIG. 2. Photograph of a typical event taken from a distance of $10 \mathrm{~m}$ using a 15 $\mathrm{cm}$ lens with $f / 8$. Eastman Kodak Linagraph Shellburst film was used and fleveloped at $7.5 \mathrm{~m} / \mathrm{min}$ in DuPont extra fast $x$-ray developer at $28^{\circ} \mathrm{C}$.
Transistors $Q 6, Q 7$, and $Q 9$ are $30 \mathrm{~W}$ units ${ }^{\hat{b}}$ with $\beta>100$ and gain-bandwidth products of $30 \mathrm{Mc}$ at collector currents of $1 \mathrm{~A}$. Transistors Q8 and $Q 10$ are $150 \mathrm{~W}$ units $^{7}$ with $\beta>10$ at collector currents of $10 \mathrm{~A}$; the gain-bandwidth product is in the vicinity of $1 \mathrm{Mc}$. At collector voltages of $500 \mathrm{~V}$ these transistors are specified to have maximum collector leakage currents of $5 \mathrm{~mA}$ at $125^{\circ} \mathrm{C}$; they were, however, selected to have leakage currents of less than 0.5 $\mathrm{mA}$ at $500 \mathrm{~V}$ at $25^{\circ} \mathrm{C}$.

In the quiescent condition at least one of the inputs is held at zero voltage, cutting off $\mathrm{Q} 4$, which in turn saturates $\mathrm{Q} 5$ and cuts off Q6 and Q7. The $0.46 \mathrm{~A}$ available current supplied by Q11 and Q12 cuts off Q8, and no significant current is drawn from the $+500 \mathrm{~V}$ supply. When the base of inpuc transistor Q4 is driven positive, Q11 and Q12 cut off, and Q7 drives Q8 into saturation. As a result the output is pulled negative via diode $\mathrm{D} 1$ and capacitors $\mathrm{C} 1$ and $\mathrm{C} 2$. At the end of the square wave pulse, the output is pulled back to zero voltage by resistor R1 via transistors Q9 and $\mathrm{Q} 10$ and capacitors $\mathrm{C} 1$ and $\mathrm{C} 2$.

During a recent spark chamber experiment at the Bevatron of the Lawrence Radiation Laboratory, 44 panels with a combined lighted area of $200 \mathrm{~cm}^{2}$ were masked and utilized as fiducial marks. The panels were pulsed by $500 \mathrm{~V}$, $4.5 \mathrm{kc}$ square wave bursts of $8 \mathrm{msec}$ duration, with the maximum current ${ }^{8}$ limited to approximately $25 \mathrm{~mA} / \mathrm{cm}^{2}$ by resistors placed in series with each panel. The spark chambers and the fiducial marks were photographed on Linagraph Sheliburst film from a distance of $10 \mathrm{~m}$. using a $15 \mathrm{~cm}$ lens with an opening of $f / 8$. A typical photograph is shown in Fig. 2.

High humidity seemed to shorten the lifetime of the panels, therefore care had to be exercised so that the seals around the leads were not damaged. Panels in the close vicinity of the spark chambers were placed on grounded plates and were protected by individual current limiting resistors. When these precautions were observed, only a few failures occurred during the experiment while the panels were pulsed approximately 600000 times.9

* Supported in part by U. S. Atomic Energy Commission and by U. S. Office of Naval Research contract Nonr 1224(23).

+ National Science Foundation Predoctoral Fellow.

${ }^{1}$ A. Saulys and F. Meanley, Rev. Sci. Instr. 36, 1053 (1965)

${ }^{2}$ M. N. Kreisler, "Plastic Luminescent Panels Used as Pulsed Fiducials," Rept. No. SLAC-TN-65-37 (Stanford Linear Accelerator Center, Stanford University, May 1965).

${ }^{3}$ Measurements using a photomultiplier tube observing the light intensity indicate that the phosphor has two time constants, a short one, less than $100 \mu \mathrm{sec}$, and a longer one of about $2 \mathrm{msec}$.

"Sylvania type PPF plastic "Panelescent" lamps with green phosphor, rated at $115 \mathrm{~V}$ ac.

${ }^{5}$ Detailed documentation is available on request.

${ }^{6}$ Honeywell type MHT 6316.

7 Delco Radio type 2 N2583 (selected).

8 The capacitance of the panels is $600 \mathrm{pF} / \mathrm{cm}^{2}$, thus the current decays from its maximum value approximately exponentially with a time constant of $r=C V / I_{\max }=\left(600 \mathrm{pF}^{\mathrm{F}} / \mathrm{cm}^{2}\right) \cdot(500 \mathrm{~V}) \cdot(15 \mathrm{~mA} /$ $\left.\mathrm{cm}^{2}\right)^{-1}=20 \mu \mathrm{sec}$.

${ }^{9}$ In another experiment where the panels were operated continuously on $115 \mathrm{~V}$ ac, no failures were observed. 